\title{
Keanekaragaman Hymenoptera pada Kebun Kakao di Lembah Napu, Sulawesi Tengah, Indonesia
}

\section{(The Diversity of bees on Cacao Plantation in Napu Valley, Central Sulawesi, Indonesia)}

\author{
Fahri $^{1 *}$, Jamaluddin $^{2}$, Fitrallisan $^{3}$, dan Mihwan Sataral ${ }^{4}$ \\ ${ }^{1}$ Laboratorium Zoologi, Jurusan Biologi, Fakultas Matematika dan Ilmu Pengetahuan Alam, \\ Universitas Tadulako, Jalan Raya Soekarno-Hatta, Tondo, Palu 94117, Indonesia \\ ${ }^{2}$ Jurusan Farmasi, Fakultas Matematika dan Ilmu Pengetahuan Alam, Universitas Tadulako, Jalan Raya \\ Soekarno-Hatta, Tondo, Palu 94117, Indonesia \\ ${ }^{3}$ Program Studi Magister Biologi, Sekolah Ilmu Teknologi Hayati, Institut Teknologi Bandung, Jawa Barat \\ 40123, Indonesia \\ ${ }^{3}$ Program Studi Agroteknologi, Fakultas Pertanian, Universitas Tompotika Luwuk, Sulawesi Tengah 94715, \\ Indonesia
}

\begin{abstract}
Central Sulawesi is one of the national cacao production centers in Indonesia. The improvement of cacao productivity has been focused on control of pest and disease management, applied breeding technology, planting materials and crops regeneration, in this case the role of pollinator agent have not considered yet. This study was aimed to identify diversity of Hymenoptera in cacao farms in Lembah Napu, Central Sulawesi. The Hymenoptera were collected by used sweep net and light trap during the day and night. Four species of Hymenoptera were found belonging in two families, such as Apis cerana, Apis dorsata, Ceratina sp., and Champsomeris sp. The highest abundance of individual was present in $2^{\text {nd }}$ plot with 53 individuals $(49.07 \%)$, followed by $1^{\text {st }}$ plot i.e. 37 number of individuals (34.26\%) and the lowest abundance was in $3^{\text {rd }}$ plot i.e. 18 individuals $(16.67 \%)$. The highest insects diversity was found in 2 nd plot $\left(\mathrm{H}^{\prime}=1.19\right)$, followed by $1^{\text {st }}$ plot $\left(\mathrm{H}^{\prime}=1.12\right)$ and the lowest diversity value was in the $3^{\text {rd }}$ plot $\left(\mathrm{H}^{\prime}=0.98\right)$. The evenness of the insects found in the $3^{\text {rd }}$ plot was the highest $(\mathrm{E}=0.34)$, followed by the $1^{\text {st }}$ plot $(\mathrm{E}=0.31)$, and the lowest one was in the $2^{\text {nd }}$ plot $(\mathrm{E}=0.30)$. Ceratina $\mathrm{sp}$, have small body size, $(8-10 \mathrm{~mm}$ in body length). However, these species were not visit to the flowers, so they couldn't classified as potential pollinators of cacao flowers.
\end{abstract}

Keywords: Hymenoptera, Theobroma cacao L., Central Sulawesi

\section{ABSTRAK}

Salah satu daerah di Indonesia yang menjadi sentra produksi kakao nasional adalah Sulawesi. Peningkatan produktivitas kakao berfokus pada pengendalian hama dan penyakit, optimalisasi penerapan teknologi budidaya, penggunaan jenis tanaman tertentu atau 
peremajaan tanaman yang telah tua, namun belum mempertimbangkan agen yang membantu dalam proses penyerbukan. Penelitian ini bertujuan untuk mengetahui jenis-jenis lebah pada kebun kakao di Lembah Napu, Sulawesi Tengah. Koleksi Hymenoptera dilakukan pada siang dan malam hari menggunakan sweep net dan light trap. Ditemukan sebanyak 4 spesies Hymenoptera yang termasuk dalam 2 famili yaitu Apis cerana., Apis dorsata, Ceratina sp., Champsomeris sp. Kelimpahan individu tertinggi di plot 2 yaitu 53 individu (49.07\%), diikuti plot 1 yaitu 37 individu (34.26\%) dan plot 3 dengan kelimpahan terendah yaitu 18 individu (16.67\%). Keanekaragaman serangga tertinggi di Plot 2 yaitu $\mathrm{H}^{\prime}=1.19$, diikuti plot 1 yaitu $\mathrm{H}^{\prime}=1.12$ dan plot 3 dengan nilai terendah $\mathrm{H}^{\prime}=0.98$. Kemerataan serangga tertinggi di plot 3 dengan nilai $\mathrm{E}=0.34$, diikuti plot 1 dengan nilai $\mathrm{E}=0.31$, dan plot 2 dengan nilai terendah $\mathrm{E}=0,30$. Lebah yang memiliki ukuran tubuh kecil yaitu Ceratina sp. dengan ukuran 8-10 mm. Namun dari segi perilaku kunjungan, Ceratina sp. tidak mengunjungi bunga kakao, sehingga lebah tersebut belum dapat disimpulkan sebagai lebah penyerbuk kakao yang potensial, meskipun memiliki ukuran yang kecil.

\section{Kata Kunci : Hymenoptera, Theobroma cacao L., Sulawesi Tengah}

\section{LATAR BELAKANG}

Indonesia merupakan penghasil kakao (Theobroma cacao L.) terbesar ketiga setelah Ivory Coast dan Ghana (Wahyudi dkk. 2008). Sentra produksi kakao nasional adalah Sulawesi, dan menjadi salah satu tanaman unggulan karena memberi kontribusi nyata dalam meningkatkan pendapatan petani. Luas areal perkebunan kakao rakyat di Sulawesi Tengah pada tahun 2007 mencapai 206.081 ha dengan total produksi 179.575 ton (BPS Sulteng, 2008). Dengan demikian, tingkat produktivitas kakao yang diusahakan petani di Sulawesi Tengah adalah 0.87 ton/ha/tahun.

Saat ini peningkatan produksikakao berfokus pada pengendalian hama dan penyakit, optimalisasi penerapan teknologi budidaya, penggunaan jenis tanaman yang memiliki potensi produksi tinggi atau peremajaan tanaman yang telah tua
(Limbongan dkk. 1997; Limbongan dkk. 2000). Peningkatan produktifitas kakao di atas belum mempertimbangkan agen yang membantu dalam proses penyerbukan. Beberapa aspek telah dipelajari seperti serangga Forcipomyia yang berpotensi sebagai penyerbuk (Glendinning, 1972; Young 2007; O’Doherty dan Zool 2012; Adjaloo dan Oduro 2013), struktur bunga pada kakao dalam kaitannya dengan respon agen penyerbuk (Frimpong-Anin dkk. 2014).

Meskipun penyerbukan pada kakao benar-benar tergantung pada aktivitas serangga, dan studi terbaru menunjukkan hasil panen kakao ditentukan oleh penyerbukan daripada sumber tanaman (Groeneveld dkk. 2010), namun di Sulawesi Tengah belum tersedia data mengenai jenis serangga pada kakao. Penelitian ini bertujuan untuk mengetahui 
jenis-jenis Hymenoptera pada kebun kakao di Lembah Napu, Sulawesi Tengah

\section{BAHAN DAN METODE}

Penelitian dilakukan di perkebunan kakao yang berada di Desa Watumaeta (Lembah Napu) kec. Lore Utara. Desa Watumaeta memiliki ketinggian 1.200 1.400 mdpl dengan memiliki kisaran suhu $18^{\circ} \mathrm{C}-30^{\circ} \mathrm{C}$. Daerah penelitian ini memiliki tipe iklim D1 yang berarti wilayah tersebut memiliki bulan basah lebih panjang daripada bulan kering dengan jumlah curah hujan tahunan antara 2000-2500 mm. Digunakan 3 plot penelitian dengan luas $20 \times 25 \mathrm{~m} 2$ (atau setara dengan 20 pohon kakao dengan jarak tanam 5 meter). Penentuan plot tersebut berdasarkan kategori usia kebun yaitu antara 6-15 tahun setelah tanam.

Koleksi dilakukan di tiga plot kebun kakao selama musim berbunga untuk menentukan kelimpahan dan keanekaragaman spesies serangga. Tanaman yang digunakan dipilih berdasarkan ketersediaan bunga. Digunakan dua metode koleksi yaitu swep net di siang hari dan light trap di malam hari. Sampel hasil koleksi diawetkan menggunakan kertas papilot (awetan kering) dan Alkohol 70\% (awetan basah). Identifikasi menggunakan Michener (2007) dan Baker (2002) serta verifikasi di
Museum Zoologi Pusat Penelitian (PUSLIT) Biologi Lembaga Peneliti Indonesia (LIPI) di Cibinong.

Sampel yang telah dikoleksi dihitung jumlah spesies (S), kelimpahan individu (N) dan ditampilkan dalam dan gambar. Keanekaragaman Hymenoptera pada masing-masing plot dianalisis dengan indeks keanekaragaman Shannon-Wiener $\left(\mathrm{H}^{\prime}\right)$ indeks kemerataan E (Magurran,

Tabel 1. Jumlah individu Hymenoptera di kebun kakao

\begin{tabular}{|c|c|c|c|c|c|}
\hline \multirow{2}{*}{ Spesies } & \multicolumn{3}{|c|}{ Plot } & \multirow{2}{*}{$-\sum$} & \multirow{2}{*}{$\begin{array}{l}\text { Ukuran } \\
\text { Tubuh } \\
\text { (mm) }\end{array}$} \\
\hline & $\mathbf{I}$ & II & III & & \\
\hline Apis cerana. & 14 & 18 & 5 & 37 & $14-16$ \\
\hline Apis dorsata & 16 & 23 & 11 & 50 & $18-20$ \\
\hline Ceratina sp. & 6 & 9 & 1 & 16 & $8-10$ \\
\hline Champsomeris sp. & 1 & 3 & 1 & 5 & $17-19$ \\
\hline Jumlah & 37 & 53 & 18 & 108 & \\
\hline Persentase & 34.26 & 49.07 & 16.67 & & \\
\hline
\end{tabular}

5 for Windows. Selain itu, dilakukan pengukuran tubuh serangga untuk mengetahui potensi mereka sebagai penyerbuk.

\section{HASIL DAN PEMBAHASAN}

Berdasarkan pengamatan Hymenoptera pada kebun kakao, ditemukan 108 individu yang termasuk dalam 2 famili dan 4 spesies. Empat spesies tersebut ialah Apis dorsata, Apis cerana, Ceratina sp., dan Champsomeris sp. (Tabel 1, Gambar 1). Beberapa spesies lebah tersebut sering dijumpai pada tanaman lain

\section{Keanekaragaman Hymenoptera pada Kebun Kakao di Lembah Napu, Sulawesi Tengah, Indonesia}

(Fahri dkk) 
seperti pada bunga Hoya multiflora (Chasanah, 2010), Sawi (Atmowidi et al., 2007) dan pada Jarak pagar (Rianti et al., 2010) dan menempati habitat yang berdekatan dengan hutan.

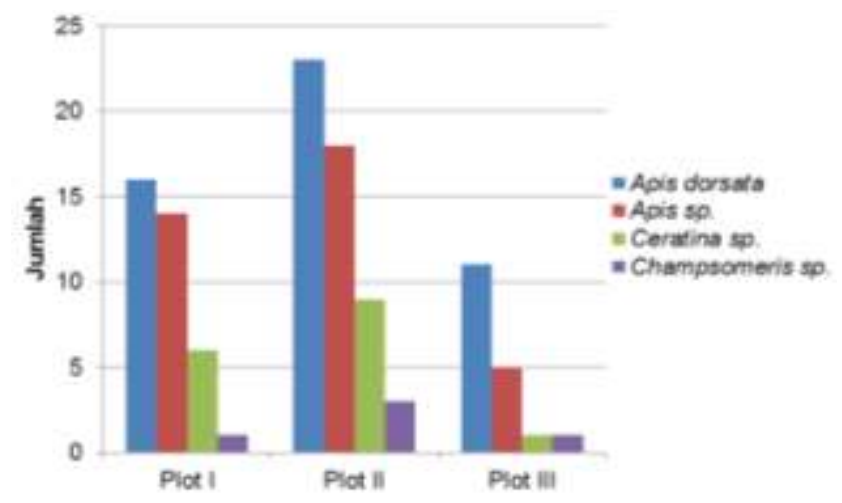

Gambar 1. Jumlah individu lebah di kebun kakao

Lokasi Watumaeta memiliki karakteristik daerah yang dekat dengan hutan hujan tropis (Taman Nasional Lore Lindu) dengan ketinggian lebih dari 1000 m.dpl. Rata-rata kelimpahan individu di plot 2 lebih tinggi dibandingkan dengan Plot 1 dan 3. Begitu pula dengan nilai keanekaragaman, Plot 2 memiliki nilai yang tinggi $\mathrm{H}^{\prime}=1.19$, diikuti Plot $1 \mathrm{H}^{\prime}=$ 1.12 dan Plot 3 dengan nilai terendah $\mathrm{H}^{\prime}=$ 0.98. Kemerataan di Plot 3 memiliki nilai yang tinggi $\mathrm{E}=0.34$, diikuti Plot $1 \mathrm{E}=0.31$ dan Plot 2 dengan nilai terendah $\mathrm{E}=0.30$ (Tabel 2, Gambar 2).

Berbeda dengan kemerataan sepesies, Plot 3 memiliki nilai yang tinggi $\mathrm{E}=0.34$, diikuti Plot $1 \mathrm{E}=0.31$ dan Plot 2 dengan nilai terendah $\mathrm{E}=0.30$ (Tabel 1, Grafik 1). Keanekaragaman tinggi di Plot 2 diduga karena selain kakao, di Plot 2 juga maih terdapat tumbuhan herba lain yang sedang berbunga yang menjadi sumber pakan bagi lebah.

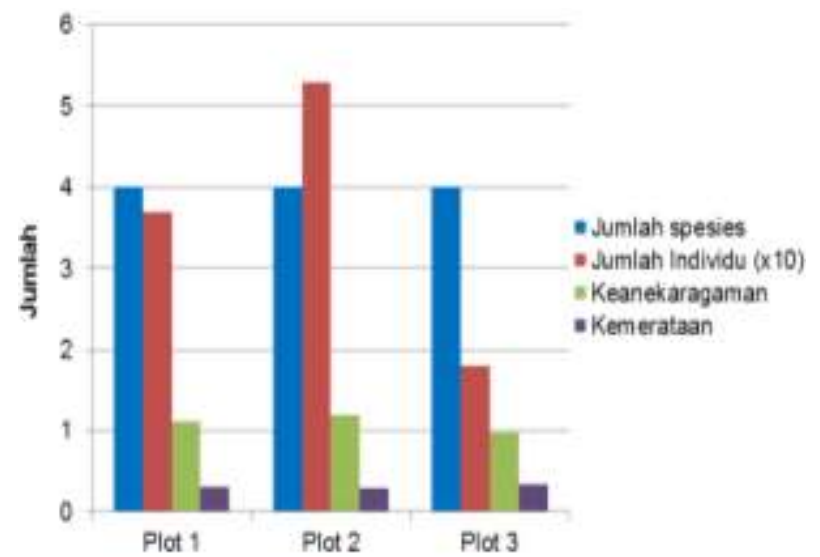

Gambar 2. Keanekaragaman lebah di kebun kakao

Apis dorsata dan Apis cerana. sebagai lebah sosial yang ditemukan dengan kelimpahan tinggi. Sola et al., (2005) melaporkan bahwa $A$. dorsata membuat sarang di pohon tinggi di dalam hutan. Selain itu, Jasmi et al., (2014) melaporkan bahwa pohon kakao merupakan salah satu pohon yang dijadikan tempat bersarang lebah A. cerana. Lokasi Watumaeta merupakan dataran tinggi sekitar 1.100 1.400 m.dpl dan dekat dengan hutan menjadi habitat yang sesuai untuk $A$. dorsata. Jarak tempuh untuk mencari pakan A. dorsata dapat mencapai $6.7-10 \mathrm{~km}$ dari sarang (Roubik, 1989) dan spesies ini merupakan penyerbuk utama tumbuhan dengan kanopi tinggi (Appanah \& Kevan, 1995).

Tabel 2. Keanekaragaman serangga di kebun kakao 


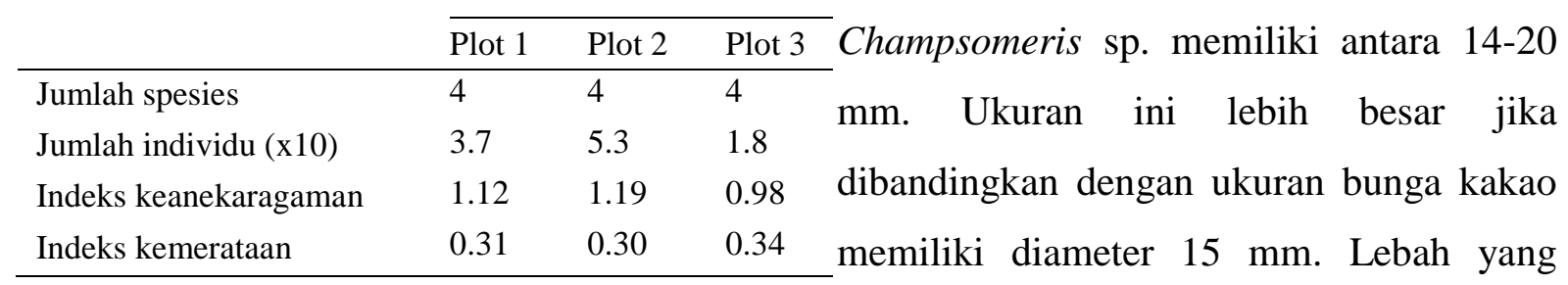

Selain Apis dorsata dan Apis cerana sebagai lebah sosial, juga ditemukan lebah Ceratina sp. sebagai lebah soliter di lokasi penelitian. Kehadiran Ceratina sp. menunjukkan bahwa lokasi tersebut merupakan habitat yang sesuai untuk tempat bersarang. Klein et al. (2003) melaporkan sarang Ceratina ditemukan di habitat yang agak terbuka dengan kelembaban rendah dan banyak tanaman herba sebagai sumber serbuksari dan nektar.

Pada penelitian ini juga ditemukan tawon Champsomeris sp. (Scoliidae) tidak mengunjungi bunga kakao namum terbang di sekitar kebun kakao. Meskipun demikin, Champsomeris sp. adalah satu-satunya penyerbuk pada anggrek Australian Calochilus campestris (Fordham, 1946; Jones and Gray, 1974), Geoblasta pennicillata (Ciotek et al. 2006). Serangga ini menjadi penyerbuk potensial pada anggrek karena bagian kepala Champsomeris sp. yang pertama kali masuk ke bunga anggrek sehingga polen dapat melekat pada bagian tersebut.

Ukuran tubuh lebah pada kisaran 8-20 mm. Lebah Apis cerana, Apis dorsata dan memiliki ukuran tubuh kecil yaitu Ceratina sp. dengan ukuran 8-10 mm. Lebah Ceratina sp. merupakan lebah soliter (Klein et al., 2008) namun beberapa spesies tersebut termasuk kelompok parasosial (Roubik, 1989). Dengan ukuran tubuh tersebut, lebah ini tidak akan kesulitan untuk mengambil nektar yang terletak di dasar bunga. Namun dari segi perilaku kunjungan, Ceratina sp. tidak mengunjungi bunga kakao, sehingga lebah tersebut belum dapat disimpulkan sebagai lebah penyerbuk kakao yang potensial, meskipun memiliki ukuran yang kecil. Lebah ini terbang di lokasi penelitian diduga karena mencari pakan pada tumbuhan lain.

\section{UCAPAN TERIMAKASIH}

Terima kasih kami ucapkan kepada kepala desa Watumaeta dan Pemilik kebun atas izin menggunakan lokasi. Penelitian ini terlaksana atas bantuan dana dari Direktorat Riset dan Pengabdian kepada Masyarakat, Direktorat Jenderal Penguatan Riset dan Pengembangan, Kementerian Riset, Teknologi, dan Pendidikan Tinggi pada Skim Penelitian Dosen Pemula tahun 2016.

\section{DAFTAR PUSTAKA}

\section{Keanekaragaman Hymenoptera pada Kebun Kakao di Lembah Napu, Sulawesi Tengah, Indonesia}

(Fahri dkk) 
Adjaloo, M.K., Oduro W., 2013, Insect Assemblage and The Pollination System of Cocoa (Theobroma cacao L.), J. Appl. Biosci, 62: 4582 4594.

Appanah, S., Kevan P.G., 1995, Bees and the natural ecosystem. Di dalam: Kevan PG, editor. The asiatic hive bee: apiculture, biology, and role in sustainable development in tropical and subtropical Asia. Ontario: Enviroquest Ltd.

Atmowidi, H., Buchori, D., Manuwoto. S., Suryobroto, B., Hidayat, P., 2007, Diversity of pollinator insects in relation to seed set of mustard (Brassica rapa L.: Cruciferae). HAYATI J Biosci 14(4):155-161

Badan Pusat Statistik, 2008, Sulawesi Tengah Dalam Angka. Kantor Pusat Statistik Provinsi Sulawesi Tengah, Palu.

Baker, D.B., 2002, On Sulawesi Ceratina (Ceratinidia) (Hymenoptera, Apoidea, Anthophoridae), Beiträge zur Entomologie 52(2): 337-345.

Ciotek, L., Giorgisa, P., Benitez-Vieyrab S., Cocucci A.A., 2006, First confirmed case of pseudocopulation in terrestrial orchids of South America: Pollination of Geoblasta pennicillata (Orchidaceae) by Campsomeris bistrimacula (Hymenoptera, Scoliidae), Flora. 201: 365-369.

Fordham, F., 1946, Pollination of Calochilus campestris, Victorian Nat. 62: 199-201.

Frimpong-Anin, K., Adjaloo, M.K., Kwapong, P.K., Oduro W., 2014,
Structure and Stability of Cocoa Flowers and Their Response to Pollination, Journal of Botany : 1-6.

Glendinning, D.R., 1971, Natural Polination of Cocoa, New Phytol, 71 : 719-729.

Groeneveld, J.H., Tscharntke T., Moser, G., and Clough, Y., 2010, Experimental evidence for stronger cacao yield limitation by pollination than by plant resources, Perspectives in Plant Ecology, Evolution, and Systematics, 12:183-191.

Jasmi., Salimah, S., Dahelmi., Syamsuardi., 2014, Nesting sites of Apis cerana Fabr. (Hymenoptera: Apidae) in two different altitudes of polyculture plantations in West Sumatera. HAYATI J. Biosci. 21(3): 135-143.

Jones, D.L., Gray, B., 1974, Pollination of Calochilus holtzei F. Muell, Am. Orchid Soc. Bull. 43: 604-606.

Klein, A.M., Dewenter I.S., Tscharntke T., 2003, Bee pollination and fruit set of Coffea arabica and $C$. Canephora (Rubiaceae), Am J Bot. 90:153-157.

Klein, A.M., Cunningham, S.A., Bos, M., Dewenter I.S., 2008. Advances in pollination ecology from tropical plantation crops, Ecology. 89(4):935-943.

Limbongan, J., Bunga, Y., Idrus, M., Martono, J., Basrum, 2000, Pengkajian sistem usahatani dan perbaikan mutu kakao di Sulawesi Tengah, Balai Pengkajian Teknologi Pertanian Biromaru, Palu.

Limbongan, J., Chatijah, Ardjanhar, A., Joseph, F.G.H., 1997, Uji lapang

\section{Keanekaragaman Hymenoptera pada Kebun Kakao di Lembah Napu, Sulawesi Tengah, Indonesia}

(Fahri dkk) 
rehabilitasi tanaman kakao secara vegetatif dengan metode sambung samping, Balai Pengkajian Teknologi Pertanian Biromaru, Palu.

Magurran, A.E., 2004, Measuring biological diversity, Blackwell Publishing, Oxford.

Michener, C.D., 2007, The Bees of the world : Second Edition, Baltimore: John Hopkins University Press, US.

O’Doherty, D.C, and Zoll, J.J.K., 2012, Forcipomyia hardyi (Diptera: Ceratopogonidae), a Potential Pollinator of Cacao (Theobroma cacao) Flowers in Hawaii, Proceedings of the Hawaiian Entomologycal Society, Vol $44: 79$ $-81$

Rianti, P., Suryobroto, B., Atmowidi, T., 2010, Diversity and effectiveness of insect pollinators of Jatropha curcas L. (Euphorbiaceae), HAYATI. J Biosci, 17(1):38-42

Roubik, D.W., 1989, Ecology and Natural History of Tropical Bees, New York: Cambridge Univ. Press.

Wahyudi, T., Panggabean, T.R., Pujianto, 2008. Kakao: Manajemen Agribisnis dari Hulu hingga Hilir, Penebar Swadaya, Jakarta.

Young, A.M.. 2007, Nature in the Cacao: Mysteries of Pollination. p. 115-162 in Young, A.M., The chocolate tree: a natural history of cacao, Florida: University Press of Florida.

\section{Keanekaragaman Hymenoptera pada Kebun Kakao di Lembah Napu, Sulawesi Tengah, Indonesia}

